\title{
The Retroductive Cycle: The research process in poststructuralist discourse analysis ${ }^{1}$
}

\author{
Jason Glynos \& David Howarth
}

Ref: Glynos, J. and Howarth, D. (2018) 'The Retroductive Cycle: The research process in poststructuralist discourse analysis', in Marttila, T. (ed.) (2018) Discourse, Culture and Organization: Inquiries into Relational Structures of Power, London: Palgrave

\section{Introduction}

It is often claimed that poststructuralist or post-Marxist discourse theory suffers from a number of methodological deficits (e.g. Keller, 2013; Marttila, 2015; 2016). These pertain mainly to its alleged incapacity to explain phenomena, where explanation is usually couched in causal terms, and to develop meaningful research strategies that can justify the accounts it puts forward. At best, poststructuralist discourse theory can re-describe phenomena with its own categories, or at worst it is concerned to develop 'high theory' which does not connect easily to the empirical world. In Logics of Critical Explanation (Glynos and Howarth, 2007), we respond to these charges by arguing that retroduction offers us a distinctive form of explanation within the context of poststructuralist discourse analysis, while the articulation of logics provides the means to flesh out the content of explanations made in its name. Here we focus on the form of explanation.

We suggest that an appeal to retroductive reasoning as a form of explanation distinct from induction and deduction can help frame the strategic and methodological issues of any research that takes seriously an anti-essentialist ontology rooted in poststructuralist discourse theory. Anti-essentialism captures the view that societies and social agents - indeed, history itself - do not contain essences - invariable and fixed properties of an object - that can be rationally extracted and used to characterize social phenomena. At the same time, although prominent in debates over how best to understand the production of theories and hypotheses in the natural sciences, we also argue that the concept of retroduction is relevant to a set of debates in the philosophy of social science. More precisely, it offers theoretical resources to develop a post-positivist picture of the study of social and political phenomena, thus furnishing important elements of a feasible and critical research strategy. We draw on arguments associated with a poststructuralist discourse-theoretical approach to social and political research (Glynos \& Howarth 2007) to justify adopting the idea of a retroductive 'cycle'. A retroductive understanding of the relationship between key elements of the social science research process offers us a useful way to think about research strategy and methodology from the point of view of post-positivism, including approaches informed by poststructuralist discourse theory.

\section{The Positivist Hegemony: Contexts of Discovery and Justification}

Many affirm a dualistic picture of natural scientific practice, whether they are philosophers of science or practitioners engaged in day-to-day scientific activities (Popper, 1961; Reichenbach, 1938). In this view, first there is a process of scientific discovery, which entails the production of a hypothesis or theory (the so-called 'context of discovery'). And this is followed by careful empirical testing, whose aim is to justify the acceptance or rejection of a hypothesis or theory (the so-called 'context of justification'). Philosophers of science can and often do disagree about the character of 'proper' science. For example, Hans Reichenbach -

\footnotetext{
${ }^{1}$ This essay draws on and develops key aspects of Chapters 1 \& 6 in Glynos and Howarth (2007). .
} 
usually identified as the first person to formalize the distinction between contexts of discovery and justification - suggested that establishing an inductive relation between empirical data and a discovered theory was the mark of a properly scientific mode of reasoning. A more common view, now rather dominant in the academy, suggests that the essence of scientific practice lies on the side of justification, not discovery. The idea here is that a process is to be understood as properly scientific only if a hypothesis has been subjected to rigorous and vigorous attempts to verify and/or falsify it. Only insofar as it has survived such tests can it be accepted as 'scientific', however provisionally, and thus be deployed legitimately to explain or predict phenomena through deduction. This idea is neatly and paradigmatically expressed by Karl Popper (1961: 135):

[I]t is irrelevant from the point of view of science whether we have obtained our theories by jumping to unwarranted conclusions or merely by stumbling over them (that is, by 'intuition'), or else by some inductive procedure. The question, 'How did you first find your theory?' relates, as it were, to an entirely private matter, as opposed to the question, 'How did you test your theory?' which alone is scientifically relevant.

This picture of natural scientific practice can be readily deployed to generate a positivist picture of social scientific practice, at least insofar as positivism is understood to subscribe to the ideal of 'unity of method'. For purposes of this text, then, we take positivism to be a doctrine comprising the following three components:

(1) It affirms a two-part picture of natural scientific practice, comprising contexts of discovery and justification.

(2) It dismisses the process of discovery as irrelevant from the point of view of natural scientific practice, while affirming as decisive the justificatory process of empirical testing (whether in the mode of confirmation or falsification).

(3) It adopts this justification-based, two-part image of natural scientific practice as a model for social scientific practice.

Although there are clear tensions in his work on this point (e.g., Gray, 1989: Chapter 2), Popper (1961: 135) appears to subscribe to just such a positivist image and ideal, explicitly declaring that his aforementioned view on the nature of scientific practice 'is not only true for the natural but also for the social sciences'.

It has been important to establish the general parameters of this understanding of natural scientific practice and its (positivist) relation to social science, because our affirmation of retroductive reasoning contests this positivist perspective. Instead, we develop a postpositivist picture of social science practice, which is capacious enough to accommodate poststructuralist, hermeneutic and other non-positivist and anti-positivist approaches to research. Of course, positivism has for a long time been criticised by advocates of hermeneutics, critical realism, and other perspectives as well. At the same time, some approaches, most notably critical realism, have explicitly employed the category of retroduction to develop a conception of explanation that rivals the inductive and hypotheticodeductive-nomological conceptions associated with positivism (Harré, 1961; Bhaskar, 1998; Blaikie, 1993, 2000; Sayer, 1983: 116-7). Given that retroduction is a term originally countenanced in the domain of natural science, and given that critical realism assumes a degree of deep ontological continuity running from the natural to the social world, the deployment of the term by critical realists in the social science domain is relatively 
unproblematic. In contrast, our own argument builds on existing work that affirms a shift in ontology from the natural to the social world. Seen in these terms, we thus demand a more careful consideration of the conditions for deploying the category of retroduction in understanding social science practice. Once accomplished, this will open up a space within which to think about a post-positivist understanding of research strategy and methodology, relevant not just from the point of view of critical realism, but from the point of view of critical social scientific research more generally, inclusive of hermeneutics and poststructuralism.

But in order to understand why and how retroduction can be made relevant to critical social scientific research, we should begin by understanding the meaning and significance attributed to retroduction in the philosophy of natural science. Although Aristotle has been credited with its original identification, retroduction has been insightfully described, developed and applied in the philosophy of natural science by Charles Sanders Peirce and Norwood Hanson. It is to these discussions and debates that we now turn.

\section{Retroduction in Natural Science}

One way to get at an initial approximation of the concept of retroduction is to contrast it with two competing modes of reasoning - deduction and induction - and to consider how the introduction of retroduction thereby raises some important issues about the nature and philosophy of science. Charles Sanders Peirce (1960) offers definitions of these three modes of reasoning. He begins with deduction, which

is that mode of reasoning which examines the state of things asserted in the premises, forms a diagram, of that state of things, perceives in the parts of that diagram relations not explicitly mentioned in the premises, satisfies itself by mental experiments upon the diagram that these relations would always subsist, or at least would do so in a certain proportion of cases, and concludes their necessary, or probable, truth (Peirce, 1960: 28)

Consider a two-dimensional figure, a triangle for example. This can be understood diagrammatically to comprise 3 non-identical, non-parallel, straight lines, all joined at their extremities to form one unbroken boundary. A series of 'mental experiments' can then be made 'upon the diagram', which would show that, no matter the variation across different triangle diagrams, a particular 'relation' between these lines (say, the sum of all its angles) 'would always subsist' (as 180 degrees). By contrast, induction

is that mode of reasoning which adopts a conclusion as approximate, because it results from a method of inference which must generally lead to the truth in the long run. For example, a ship enters port laden with coffee. I go aboard and sample the coffee.... I conclude by induction that the whole cargo has approximately the same value per bean as the hundred beans of my sample (Peirce, 1960: 28)

Finally, we can turn to retroduction, which Peirce (1960: 29) understands as 'the provisional adoption of a hypothesis'. Here it is interesting to note that Peirce often uses the term hypothesis interchangeably with retroduction. As he puts it, '[t]he great difference between induction and hypothesis is that the former infers the existence of phenomena such as we have observed in cases which are similar, while hypothesis supposes something of a different kind from what we have directly observed, and frequently something which it would be 
impossible for us to observe directly' (Peirce, 1960: 385). ${ }^{2}$ The fact that the hypothesis $(\mathrm{H})$ introduces something 'different in kind' into the mix is important because it implies that this foreign element cannot in any way be induced from observational data, even though it is provoked by those observations (P). In other words, the hypothesis cannot be inferred until its content is already present in the explanation of $\mathrm{P}$. The philosopher of science Norwood Hanson makes a similar point. He highlights the way retroduction contrasts not only with inductive accounts, which 'expect $\mathrm{H}$ to emerge from repetitions of $\mathrm{P}$ ', but also with H-D [hypothetico-deductive] accounts, which "make $\mathrm{P}$ emerge from some unaccounted-for creation of $\mathrm{H}$ as a "higher-level hypothesis" (Hanson, 1961: 86). In sum, while deductive reasoning proves what is the case, and inductive reasoning approximates what is the case, retroductive reasoning conjectures what is the case (Peirce in Hanson, 1961: 85).

Having fixed the concept of retroduction, we can now ask what exactly its role has been in discussions about the philosophy and sociology of natural science. The simple reply to this question is that the concept of retroduction has been invoked primarily as a way to better capture the process by which scientists produce hypotheses and construct theories. From the point of view of the dichotomous picture of natural scientific practice outlined earlier, the primary focus of this debate centres on the context of discovery. Given this context, advocates of retroduction contest two positions. The first position is embodied by those who claim that the discovery process is best captured by the logic of induction. In contrast to this, advocates of retroduction insist that the latter offers a more plausible account of the logic of discovery. 'Physicists rarely find laws by enumerating and summarising observables', argues Hanson. Although 'they start from data' scientists form hypotheses whose content exceeds those observations (Hanson, 1961: 70). The second position, however, is embodied by those who claim that the discovery process has no logic at all or, to put it more modestly, has no necessary logic. As Popper (1980: 31) expresses it in one of his formulations,

the act of conceiving or inventing a theory, seems to me neither to call for logical analysis nor to be susceptible of it. The question how it happens that a new idea occurs to a man ... may be of great interest to empirical psychology; but it is irrelevant to the logical analysis of scientific knowledge. This latter is concerned not with questions of fact . . . but only with questions of justification or validity . . . Its questions are of the following kind. Can a statement be justified? And if so, how? Is it testable? Is it logically dependent on certain other statements? Or does it perhaps contradict them? ... Accordingly I shall distinguish sharply between the process of conceiving a new idea, and the methods and results of examining it logically.

The question here is whether there is in fact a 'logic' to the process of theory construction, in which case this process cannot simply be dismissed as whimsical or irrelevant from a scientific point of view, as Popper appears to believe. The suggestion by philosophers of science like Norwood Hanson is that there is in fact a logic to the process of theory construction and the production of hypotheses, and that retroduction, as a mode of reasoning, best captures this logic. As Peirce puts it, retroduction is a 'logical inference, asserting its conclusion only problematically, or conjecturally, it is true, but nevertheless having a perfectly definite logical form' (Peirce in Hanson, 1961: 86). Though more open-ended than deduction and induction, retroduction describes a non-trivial, distinctive mode of reasoning. Moreover, not only does an appeal to retroduction better describe the way scientists go about

\footnotetext{
${ }^{2}$ For a useful critical and clarificatory note on Peirce and retroduction, see Frankfurt (1958).
} 
their business, but it also supplies a corrective to the way scientific practices are understood by philosophers and sociologists of natural science.

This completes our account of the role retroduction plays in discussions and debates in the philosophy and sociology of natural science. To understand what role retroduction can play in the philosophy and sociology of social sciences, it is important to highlight how, despite Popper's and Reichenbach's opposing views regarding the demarcation criterion of natural science (deduction versus induction), and despite Hanson's and others' opposing views regarding theory construction (the logic of retroduction versus the logic of induction versus no logic at all), all are united in maintaining the two-part picture of science introduced by Reichenbach, comprising the contexts of discovery and justification. At first sight, of course, this suggests that the usefulness of retroductive reasoning in helping us to generate a new model of explanation in social and political analysis is potentially limited due to its restriction to the process of theory-construction and thus the context of discovery. In order to show that the value of retroduction in the social sciences is broader than this, we shall contest the sharp distinction that is drawn between the contexts of discovery and justification. This, then, is the task of the next section.

\section{Retroduction in Social Studies: From 'externality' to 'internality'}

The argument about how and why the maintenance of a stark separation between the contexts of discovery and justification is unsustainable in the social sciences rests on a premise shared by many who contest the use of the causal law paradigm in social science research. This premise can be cast in terms of a 'minimal' hermeneutical constraint imposed on any social science explanation. In this view, any explanation of a social phenomenon must 'pass through' (i.e., take into account in a non-trivial way) the self-interpretations of the actors engaged in affected practices, even if such explanations are not reducible to those selfinterpretations (Glynos and Howarth, 2008: 21). The idea that self-interpretations should be seen as both necessary for and constitutive of a social science explanation is embraced by a wide range of traditions, including hermeneutics, critical realism, and poststructuralism; but it also resonates strongly with a number of frequently expressed reasons to be sceptical about maintaining methodological continuity across the natural and social science, or to put it differently, about sustaining a strong separation between the contexts of discovery and justification. These reasons variously emphasize:

(1) the centrality of self-interpretations in the social world;

(2) the irreducibility and complexity of context in attributing sense and significance to 'data' against which hypotheses are tested;

(3) the contestability of the ontological presuppositions necessarily brought to bear when self-interpretations and data are subjected to interpretation.

In what follows, we offer one version of the argument that there is a 'minimal hermeneutic' constraint in the social and human sciences, which challenges the positivist image of science in which there is a clear separation of discovery and justification, and a prioritisation of the latter. We suggest that this dualistic picture, and the causal paradigm that it sustains, relies on the (contestable) idea that the relationship between a process (whether social or natural) and its context is understood to be 'external'. Instead, we argue that, unlike many cases in the natural science field, a social process and its context should be seen (presumptively) as co- 
constitutive and, in this sense, 'internal' (e.g. Putnam, 1987; 1988; Marttila, 2016: Chapter $5)$.

We can elaborate upon this argument by examining first how the causal law model informs our understanding of processes in the natural world. The basic intuition can be stated simply: the way a causal sequence or process functions in the natural world is understood to be independent of the meaning of that process. The way the law of gravity operates, for example, is independent of what you or I think of it. The moment, however, the meaning of a process becomes a key part of how it functions, its status as a causal law is put into question. And this is precisely what happens when we move from the natural world to the social world.

Using the law of gravity to explain why an apple falls to the ground implies that the law and the context have an 'external' relation to one another. That is to say, changes in the context do not change the way the law functions (i.e. the identity of the natural process). Changes in the context only change the outcomes or effects of the natural process (causal law). I may hold the apple at a greater height, then at a lower height. This variation of contextual conditions can be used as a way of 'testing' the law treated as a hypothetical law, or the law now detached from its context of discovery - can be used to explain the variation in outcomes as a function of the variation of context. The essential point here is that, in many natural science scenarios, the relation between natural process and context is treated as 'external'. References to the causal law paradigm invariably seek to capture this aspect of the relationship between process and context.

Of course, the relationship between natural processes and context may often be very complex and impossible to disentangle. Biologists, for example, are always at pains to emphasize complexity, often making it impossible to sufficiently control for contextual factors sufficiently in our attempts to determine the identity of a causal law. The presumption of 'externality', however, remains intact. And it is this relation of 'externality' that is central to maintaining the distinction between context of discovery and context of justification. This is important from the point of view of a justification-centred, two-part image of social scientific practice, because it is only insofar as a posited hypothesis can be fully extracted ('externalised') from one context (the context of discovery), that it can then be properly and independently tested in another (the context of justification).

In the social world, however, social processes do not have the status of causal laws because their relation to context is not external. More specifically, social processes and context are mediated by subjects and their meanings. Processes and contextual factors are treated as relational features that over-determine one another, rather than discrete as atoms that have an external relation to one another. This ontological difference has capital consequences. It means, in particular, that the very identity and operation of a social process is contextdependent. It is not merely the outcome or effects of a social process that are contextdependent. The very identity and functioning of the social process is at stake here: the posited social process is dependent on the context of its operation, and the context of its operation is dependent on the meanings attributed to it by the relevant subjects. But if the identity and operation of a hypothesized social process cannot be clearly severed from the contextualsignifying features of its discovery, these features will have some role to play in the context of justification (i.e. the posited social process cannot be simply detached or 'externalised' from the context of discovery). In the social world, therefore, the boundary between contexts of discovery and justification is blurred, and this points to the need to abandon the positivist image of social science practice. This suggests we should opt instead for a more capacious, 
post-positivist image of social science practice, in which meaning is acknowledged to have a constitutive role to play in the identity and operation of social processes.

In this view, appealing to a social process to explain a phenomenon (e.g., why a particular state has a two party system) is not the same as using the law of gravitation to explain why an apple falls to the ground. The difference between these two types of explanation resides in the role that subjectivity and meaning play in mediating the process at stake and the contextual features within which it is operative. Even where political scientists claim to have established laws or 'strong probabilistic tendencies' - Duverger's law or Roberto Michels's 'iron law of oligarchy' for example - it is possible to show how they in fact offer often rather nuanced meaning-mediated and context-dependent analyses. In short, the covering-law model 'reflectively misunderstands the logic of political explanations' (Farr, 1987: 61), while a post-positivist picture better captures the character of social processes, as well as the way many social science scholars think and talk and analyse social processes.

Such a post-positivist image points to reasons why prediction - the holy grail of positivist social science practice - is so fraught with difficulties. However, from the point of view of the post-positivist perspective we are sketching out, the sources of these difficulties are not merely empirical, but also ontological. It is certainly true that predictions in the social world are dependent on the beliefs of subjects and that such predictions are therefore as fragile or as stable as those beliefs are. However, this sort of fragility - or temporary stability - is something that can be readily accommodated by means of probabilistic-statistical forms of calculation and prediction. There is, however, a 'second-order' fragility that we can add to this, whose source is the subject's capacity for second-order reflexivity frequently emphasized by those who take seriously a hermeneutical ontology (cf. Glynos and Howarth, 2007: 220-1, note 21; Marttila, 2016: Ch. 5; Zienkowski, 2017). Such second order reflexivity generates paradoxical effects familiar to most social scientists aiming to deliver robust predictions: the so-called 'feedback effects' (Jervis 1997) or 'looping effects' (Hacking, 1995). These paradoxical effects point to the contingency that is introduced into an object of investigation, as soon as its logic, predicted behaviour, or character - however probabilistic in character or however reasonable its underlying rationale - is made public and thus accessible to the subjects being studied. ${ }^{3}$ Consider, for example, cases of so-called 'selffulfilling' and 'self-defeating' prophecies. As an example of a 'self-defeating' prophecy imagine a dictum which states that queues in theme parks peak on bank holidays. This would exemplify the case of a self-defeating prophecy if the wide dissemination of the dictum served to provide a good number of people with a reason to avoid theme parks on bank holidays. Acting on such knowledge would thus produce a new and contrary dictum stating that queues in theme parks shrink on bank holidays. In other words, in the social sciences the contextual features - including the self-interpretations of the relevant social actors - serve as conditions of possibility of behavioural patterns that are strongly bound up with the content, and therefore the meaning and significance, of the hypotheses and explanations themselves.

\footnotetext{
${ }^{3}$ The openness and fragile character of the social world, however, does not entail abandoning the explanatory aims of social science. An emphasis on possibility, as opposed to probability, makes it possible to disarticulate prediction from explanation. For this reason scholars such as Bhaskar affirm the aims of social science to 'be explanatory and non-predictive. (Particularly important here will be the capacity of a theory (or research programme) to be developed in a non-ad hoc way so as to situate, and preferably explain, without strain, a possibility once (and perhaps even before) it is realized, when it could never, given the openness of the social world, have predicted it.)' (Bhaskar, 1998: 46)
} 
Of course, these second order reflexivity effects can produce a desire to generate predictions that are 'publicity-proof' or 'publication-proof'. But it can also produce a more questionable desire, namely, to keep such predictions from public view. As Connolly (1981: 20) observes, from this perspective

to render the predictions reliable the expert is encouraged to keep established correlations outside the sphere of public discourse. For given the reflexive capacities of the human objects of inquiry, widespread awareness of the antecedents of their own behaviour might provoke them to revise future patterns of conduct. The awareness could diminish both the ability to test the law-like claim (since one of its preconditions has changed) and the ability to use the knowledge effectively in social policy.

What both first order and second order fragility have in common is the idea that subjects both can know their beliefs and have the capacity to adjust them in light of new information and in line with their ideals and objectives. At the very least, then, we could say that unlike the natural sciences, so-called laws and explanations in the social sciences are inextricably tied to the subjects they purport to cover, such that hypotheses comprise both explanatory elements and the conditions under which these explanations hold. In addition, however, we could say here that a poststructuralist perspective points to a more 'radical' contingency and thus a third order fragility, beyond the second order fragility that a hermeneutical perspective makes apparent, linked to the constitutively incomplete or open character of belief systems as such. This generates effects which are not necessarily easily distinguishable from the second order effects we have described above, but it does seek to (quasi-transcendentally) account for such effects in terms of our negative, anti-essentialist ontology.

An important objective of this section was to offer reasons to doubt the stark separation between the contexts of discovery and justification presupposed by positivist approaches to social science research, suggesting that a key source of these reasons lies in the distinctive ontologies underpinning the natural and social worlds. ${ }^{4}$ We are now in a position to discharge its other objective, namely, to draw out the implications of this exercise from the point of view of retroduction. Retroduction was irrelevant from the point of view of justification, which was understood to follow a different logic. Since, however, the autonomy of the two contexts of discovery and justification is not sustainable in a social science context, retroduction becomes relevant to both contexts and must therefore be understood to partake in the entire arc of social scientific practice. In contrast to the two-part picture of positivist social science, comprising a logic of scientific discovery followed by a logic of justification made up of exhaustive empirical testing, we suggest it is better to conceive of social science practice as entailing one overarching logic of investigation - what we call a 'retroductive cycle'. 5

\footnotetext{
${ }^{4}$ As far as this essay is concerned, we are agnostic as to whether the stark separation between contexts of discovery and justification is sustainable even in the natural sciences. Our argument does not rely on this. Our argument takes as its target a particular image of doing natural science that is deployed rather rigidly to frame our understanding social science practice, irrespective of whether this image stands up to scrutiny. We have adduced reasons about why this image is not appropriate when applied to the social sciences, but this does not preclude the possibility of adducing reasons that contest the suitability of this image even for characterizing natural science practice, particularly when one considers how heterogeneous and expansive this field is, extending well-beyond Newtonian physics as the stereotypical image of natural science.

${ }^{5}$ In our book, we conceptualize the cycle in terms of a meta-methodological logic comprising three overdetermined activities: problematizing empirical phenomena; accounting for these phenomena; and persuading - and/or intervening into - the relevant community and practices of scholars and practitioners. Thus,
} 
Retroduction is understood as a cycle - a kind of restless 'spiral'- because as we move from one 'moment' to the next, and back again, revising aspects of our account in light of adjustments made in other moments, we never return to the same spot. ${ }^{6}$ A post-positivist 'one logic' picture suggests that there is an essential relation of over-determination - and to-andfro movement - between each moment of the social science research process. This is in no small part because the persuasive aspect of justification extends to the task of convincing the relevant audience about the way a research problem was characterized (or re-characterized) in offering an explanatory account in the first place, pointing us back to the context of discovery. This contrasts with positivism's two-part picture of social science research practice, which treats processes of discovery and justification as entirely autonomous and separate from one another, but where strict adherence to a logic of justification (usually in terms of a carefully defined 'testing' methodology) can deliver robust and stable judgements in a way that is not at all dependent on the process of discovery.

\section{Implications for Research Strategy}

A rejection of the stark boundary between the contexts of discovery and justification, however, does not entail rejecting the use of the terms discovery and justification, no more than it does entail rejecting other terms associated with the positivist framework. It only transforms their meanings and significance. Justification is still crucial, and robust social science research is still something that can and should be espoused, but the status and meaning of the elements of justification shift when viewed through a post-positivist lens. In this view, the basic elements of justification remain the same, but the choices we make in relation to those elements are no longer governed by the narrow epistemological-cummethodological imperative to produce and/or test falsifiable predictions. Elements of justification are thus interpreted in line with research purposes that can range far beyond these particular epistemological objectives, to include those that are ineliminably historical, ontological, political, and ethical. Such a shift in objectives will generate shifts in the meaning and status of terms such as 'least likely' or 'most likely' when justifying the selection of a suitable 'test case', for example. Likewise, the meaning and status of case selection qualifiers such as 'extreme', 'deviant', or 'paradigmatic', can and will vary enormously as a function of presupposed ontological commitments, as well as the uses to which they can be put, be they to generalize, elucidate, reveal, critique, or emancipate. And what we say here in relation to case selection can be said also in relation to any number of other elements of justification, including case organization, corpus selection, the reliability of

the practices of persuasion cannot - except heuristically - stand outside the retroductive cycle (cf. Glynos and Howarth, 2017: Chapter 1).

${ }^{6}$ The idea of 'retroductive cycle' differs from the notion of a 'hermeneutic circle' (cf. Shklar, 2004[1986]) in a number of important respects. First, the term cycle, as opposed to circle, emphasizes how each moment of relative equilibrium reached in the to-and-fro movement of retroduction is always a 'return' to a different point, thus pointing to an inherent openness in the process. A 'hermeneutical circle', in contrast, can sometimes carry with it the connotation of a closed or asymptotically 'final' or 'correct' interpretive fit between text and context. Second, the qualifier 'retroductive', at least as we have adapted it to a social science context, explicitly links hypothesis to problematization and persuasion, foregrounding the role played by ontology and subjectivity, often under-emphasized when thinking about interpretation predominantly in terms of the relation between text and context. Finally, the idea of a 'retroductive cycle' aspires to capture a process that is not exclusive to those found in the hermeneutical tradition, but whose scope of application is relevant also for other traditions of thought in social science that are critical of the causal law paradigm, including critical realist and poststructuralist traditions. 
data and choice of methodological techniques, the validity of inferences, and the style of presentation itself.

Elements of justification are thus formulated and rearticulated in each 'moment' of the retroductive cycle in a way that demonstrates how they are over-determined by aspects of the discovery process. ${ }^{7}$ While social scientists wedded to the causal law paradigm may disagree about whether findings verify or falsify predictions, post-positivist social scientists understand they are caught in an expansive retroductive cycle, where disagreement is about the very meaning and significance of findings, thus demanding critical engagement with the process of problematization itself, not to mention the ontological and normative commitments informing the way problematized phenomena should be characterized. A postpositivist image of social science practice thus paints a strikingly capacious conception of justification and testing. ${ }^{8}$ It is for this reason that we have argued that, from the point of view of a logic of retroduction operating in a social science context, 'the single most important criterion for admitting a hypothesis, however tentatively,' is simply that 'it accounts for the phenomenon or problem at stake.' (Glynos and Howarth, 2007: 26). In this view, an account is accepted as a valid explanation when its criteria can be publicly articulated and justifiedcriteria concerning evidence, consistency, exhaustiveness, and so on. The unsettling aspect of this post-positivist approach, of course, is that such criteria are themselves subject to interpretation and contestation, since they presuppose a set of commitments that cannot be resolved by appealing to ontologically and normatively neutral epistemological tests. Nothing outside the collective process of judgement-making - not even the most sophisticated methodological techniques - can guarantee its outcome.

Thus the idea of a retroductive cycle foregrounds how justification does not emerge 'naturally' or 'straightforwardly out of the methods and techniques we deploy in our research. Processes of justification themselves fold back into processes of reproblematizations, which re-inform and over-determine the purposes, strategies, and methods of our research, including our selection from, and use of, a sizeable and heterogeneous set of techniques, including discourse analytic, rhetorical, ethnographic, participatory, psychosocial, perspectival, corpus-linguistic, statistical, experimental, and survey-based techniques. From a poststructuralist point of view, the setting up of research strategies demand familiarity with a wide range of methods and techniques, but it also demands we engage in a sustained practice of reactivation, deconstruction, commensuration, and articulation. Without first carefully disembedding reified ontological and normative deposits in various methods and techniques that we seek to appropriate, we run the risk of reproducing their biases.

Generalization and comparison also comprise key elements of the justification process and for this reason do not escape the orbit of an expanded retroductive cycle. From our perspective, generalization and comparison are made possible through shared paradigms, theoretical concepts and ontological presuppositions. Importantly, however, they cannot be divorced from the moment of problematization, which is intimately connected to the

\footnotetext{
7 The concept of articulation is a crucial concept in poststructuralist discourse theory. Although it plays an important role in understanding the logic of the retroductive cycle, this has not been developed in detail in this chapter, largely due to space limitations. (See Glynos and Howarth (2007: Chapter 6) for a detailed treatment of this concept).

8 A post-positivist understanding of testing can, of course, incorporate experimental, statistical, and other mathematical techniques normally associated with natural science practice. It simply does not assign these methodological techniques any presumptive epistemological privilege that somehow allows them to 'escape' the orbit of the retroductive cycle (cf. Topper, 2005: 192-4).
} 
(contestable) purposes to which we put generalization and comparison. Generalization and comparison takes place on the basis of shared judgements about theoretical terms, about paradigms, and about what constitute cases that converge or diverge from paradigm cases. The way paradigms shed light is not straightforward because it requires that we articulate the networks of similarities and differences through a series of comparisons, justifying the claim to a generalized family resemblance in both theoretical and contextual terms. What makes possible the simultaneous singularity and generalisability of each case is the background theoretical framework and ontology informing the analysis, coupled with the practice of articulation. We explicitly couch explanatory accounts in theoretical terms, which find expression in different contexts, because they emerge out of our presupposed ontological horizon, and thus common theoretical language. This means we can formulate more general questions and hypotheses that invite further comparative research. We might ask, for example, how the specific logic we have identified in our research, such as the logic of the supermarket, might function as a paradigm in articulating and characterizing market practices in the health care sector.

One general implication of the post-positivist picture of the social science research process in terms of an overarching logic of retroduction is to highlight the fragile and rather volatile character of the 'matter' and 'knowledge' of the social world, related not only to the sheer complexity of social life, but also to the peculiar role that human subjectivity plays in social science explanation, namely, that humans are simultaneously the objects and subjects of knowledge - something Foucault captured with the expression 'empirico-transcendental doublet' (Foucault, 2004[1966]: 347). This complexity, co-constitutivity, and constitutive openness can be expressed more formally by appealing to the way some philosophers of social science draw a contrast between positivist and post-positivist forms of inference. To paraphrase Jon Elster, if a positivist covering-law explanation of an event, E, entails establishing the presence of conditions $\mathrm{C} 1, \mathrm{C} 2, \ldots \mathrm{Cn}$, then a post-positivist empirical claim would take the form 'If C1, C2, . . Cn obtain, then sometimes E' (Elster, 1999: 5; emphasis added). This 'sometimes' is crucial, playing havoc with anyone's aspiration to discover in the social world a causal law akin to gravitation. It expresses in a formal way the constitutively fragile character of the social world, highlighting the prima-facie centrality of case-based thick-descriptive attention to situational features, in part due to their internal relation to social processes, in part due to their essentially incomplete character. It implies that any social science account can only ever aspire to an equilibrium that is reflectively and constitutively temporary and unstable.

\section{Conclusion}

The importance of retroduction to researchers drawing on an anti-essentialist ontology and sensibility is that it offers scholars a language with which to construct a counter-narrative to the way positivism's suspect image of scientific practice has come to dominate many parts of the social science academy. Retroduction helps us to both relativize and question the assumption that our modes of reasoning in all forms of scientific practice are exhausted by induction and deduction. Equally, poststructuralist discourse theory, and anti-essentialist approaches to social and political research more generally, are not simply counter-posed to positivist perspectives. Instead, they can also form a chain of equivalence with other postpositivist approaches. Indeed, what poststructuralist discourse theory can share with other strands of hermeneutics, critical realism, and even neo-positivism, is a retroductive understanding of how social science is conducted - whether in practice, in theory, or both. 
The retroductive cycle thus offers a fruitful way of framing the research process, particularly as regards strategy and methodology. 
References

Bhaskar, R. (1998) The Possibility of Naturalism, 3rd edn. London: Routledge.

Blaikie, N. (1993) Approaches to Social Enquiry. Cambridge: Polity.

Blaikie, N. (2000) Designing Social Research: The Logic of Anticipation. Cambridge: Polity.

Connolly, W. (1981) Appearance and Reality in Politics. Cambridge: CUP.

Elster, J. (1999) Alchemies of the Mind. Cambridge: CUP.

Farr, J. (1987) 'Resituating Explanation', in T. Ball (ed.) Idioms of Inquiry. Albany NY: SUNY.

Feagin, J. R., Orum, A. M., \& Sjoberg, G. (1991) A Case for the Case Study. Chapel Hill: University of North Carolina Press.

Flyvberg, B. (2001) Making Social Science Matter. Cambridge: CUP.

Foucault, M. (2004[1966]) The Order of Things. London: Routledge.

Frankfurt, H.G. (1958) 'Peirce's Notion of Abduction', The Journal of Philosophy, 55(14): 593-97.

Glynos, J. and Howarth, D. (2007) Logics of Critical Explanation in Social and Political Theory. Abingdon: Routledge.

Glynos, J. and Howarth, D. (2008) 'Critical explanation in social science: A logics approach', Swiss Journal of Sociology, 54(1): 5-35.

Gray, J. (1989) Liberalisms, London: Routledge.

Hacking, I. (1995) 'The Looping Effects of Human Kinds' in D. Sperber, D. Premack, and A.N. Premack (eds) Causal Cognition. Oxford: Clarendon

Hanson, N.R. (1961) Patterns of Discovery. Cambridge: CUP.

Harré, R (1961) Theories and Things. London: Sheed \& Ward.

Jervis, R. (1997) System Effects. Princeton, NJ: Princeton University Press.

Keller, R. (2013) Doing Discourse Research. London: Sage.

Marttila, T. (2015) 'Post-foundational Discourse Analysis: A Suggestion for a Research Programme', Forum: Qualitative Social Research, 16(3:1).

Marttila, T. (2016) Post-foundational Discourse Analysis. London: Palgrave.

Peirce, C.S. (1960) Collected Papers, vols. 1 and 2. Cambridge, MA: The Belknap Press of Harvard University Press.

Popper, K. (1961) The Poverty of Historicism. London: Routledge.

Popper, K. (1980) The Logic of Scientific Discovery. London: Routledge.

Reichenbach, H. (1938) Experience and Prediction. Chicago, IL: University of Chicago Press.

Putnam, H. (1987) The Many Faces of Realism. LaSalle, IL:Open Court Publishing Company.

Putnam, H. (1988) Representation and Reality. Cambridge, MA: MIT Press.

Sayer, D. (1983) Marx's Method. Brighton: Harvester.

Shklar, J. N. (2004[1986]) 'Squaring the Hermeneutic Circle', Social Research, 71(3): 655678.

Topper, K. (2005) The Disorder of Political Inquiry. Cambridge, MA: Harvard University Press.

Zienkowski J (2017) 'Reflexivity in the transdisciplinary field of critical discourse studies', Palgrave Communications, DOI: 10.1057. 